\title{
Subcutaneous Soft Tissue Implantation of Papillary Thyroid Carcinoma after Endoscopic Thyroidectomy
}

\author{
Jihyoung Cho, Sun Hee Kang \\ Department of Surgery, Keimyung University School of Medicine, Daegu, Korea
}

Endoscopic thyroidectomy with bilateral axillo-breast approach (BABA) is a feasible method of thyroidectomy with good surgical outcome and excellent cosmetic result as compared with conventional open thyroidectomy in selective patients. Thus, endoscopic thyroidectomy is widely used in treatment of thyroid diseases. However, despite the many advantages, we sometimes encounter unexpected complication, such as neck stiffness caused by adhesion, change of sensory, seroma formation, and subcutaneous soft tissue implantation. Subcutaneous soft tissue implantation of thyroid tissue is a very rare complication of thyroid surgery. However, it is troublesome to both patient and doctor. We experienced a case of papillary thyroid carcinoma recurrence at anterior and antero-lateral subcutaneous area after endoscopic total thyroidectomy. Our case presented with a papillary thyroid carcinoma measuring $2.1 \mathrm{~cm}$ in size and showed thyroidal capsule invasion and extra-thyroidal extension on the permanent pathologic report. Therefore, we suggest that appropriate indications should be applied for an endoscopic thyroidectomy and efforts should be made to decrease tumor cell spillage in order to prevent tumor rupture, and for careful handling and protection of the extraction site.

Key Words: Subcutaneous soft tissue implantation, Papillary thyroid carcinoma, Endoscopic thyroidectomy

\author{
Received October 10, 2014, \\ Revised November 4, 2014, \\ Accepted November 19, 2014 \\ Correspondence: Jihyoung Cho \\ Department of Surgery, Keimyung University \\ School of Medicine, 56 Dalseong-ro, Jung-gu, \\ Daegu 700-712 Korea \\ Tel: + 82-53-250-7063 \\ Fax: + 82-53-250-7322 \\ E-mail: chojh0404@dsmc.or.kr
}

\section{INTRODUCTION}

Today an increasing number of domestic hospitals are carrying out endoscopic thyroidectomy instead of the existing open thyroidectomy based on changes of health concepts focusing on quality of life, an increase of early diagnoses of thyroid diseases and the development of surgical operation equipment. For patients with thyroid benign tumor and some patients with thyroid carcinoma, endoscopic thyroidectomy is safe and there was no difference shown in the treatment results if compared with open thyroidectomy.(1,2) Furthermore, superior results were shown for patient appearance.(3) Therefore, as the number of endoscopic thyroid surgeries is increased today, patients often experience post-operative complications such as adhesion, sensory changes, seroma formation and subcutaneous soft tissue implantation. Sometimes, it has been reported a needle tract implantation after fine needle aspiration cytology (FNA).(4) However, a subcutaneous soft tissue implantation of thyroid cancer tissue is very rare. Herein we report a case of PTC recurrence which was encountered around the port insertion area and subcutaneous area after endoscopic thyroidectomy.

\section{CASE REPORT}

In October 2009, a 26-year old woman was referred to our breast-endocrine surgery center for the management 
of a silent thyroid nodule (about $1.8 \mathrm{~cm}$ ). The FNA conducted at the local medical clinic confirmed a papillary thyroid carcinoma (PTC) before. The patient had neither discomfort nor symptom. We performed neck ultrasonography (USG) and neck computed tomography (CT) and identified a $17 \times 12 \times 13 \mathrm{~mm}$ sized oval-shaped, well demarcated solid nodule in the right upper portion of thyroid with a suspected thyroidal capsule invasion (Fig. 1). We reviewed the specimen slide taken from previous hospital and confirmed PTC. The patient was anxious about an anterior neck scar and therefore an endoscopic total thyroidectomy was performed by bilateral axillobreast approach.(5) No complications occurred and the patient was discharged from hospital 3 days after surgery. On the permanent pathologic report a right PTC with a tumor size of $2.1 \mathrm{~cm}$ with partial capsular invasion and extra-thyroidal extension was identified. However, the surgical margin of specimen was free from cancer cells. After surgery the patient was exposed two times to low dose radioactive-iodine ablation $(30 \mathrm{mCi})$ and a thyroid stimulating hormone (TSH)-suppression treatment was given.

In May 2010, a neck USG was conducted which revealed a $6 \mathrm{~mm}$ sized nodule in the medial border of the right sterno-cleido-mastoid (SCM) muscle and a $5 \mathrm{~mm}$ sized nodule in the anterior midline (Fig. 2A, B, D). Also a mildly hypermetabolic nodule seems to be present on the PET-CT (Fig. 2C) and so FNA was performed. In FNA was shown malignant cell presence. It was PTC metastasis and we assumed a lymph node metastasis. Under local anesthesia were excised two nodules through a small incision on the right lateral neck area without skin excision. Soft tissue
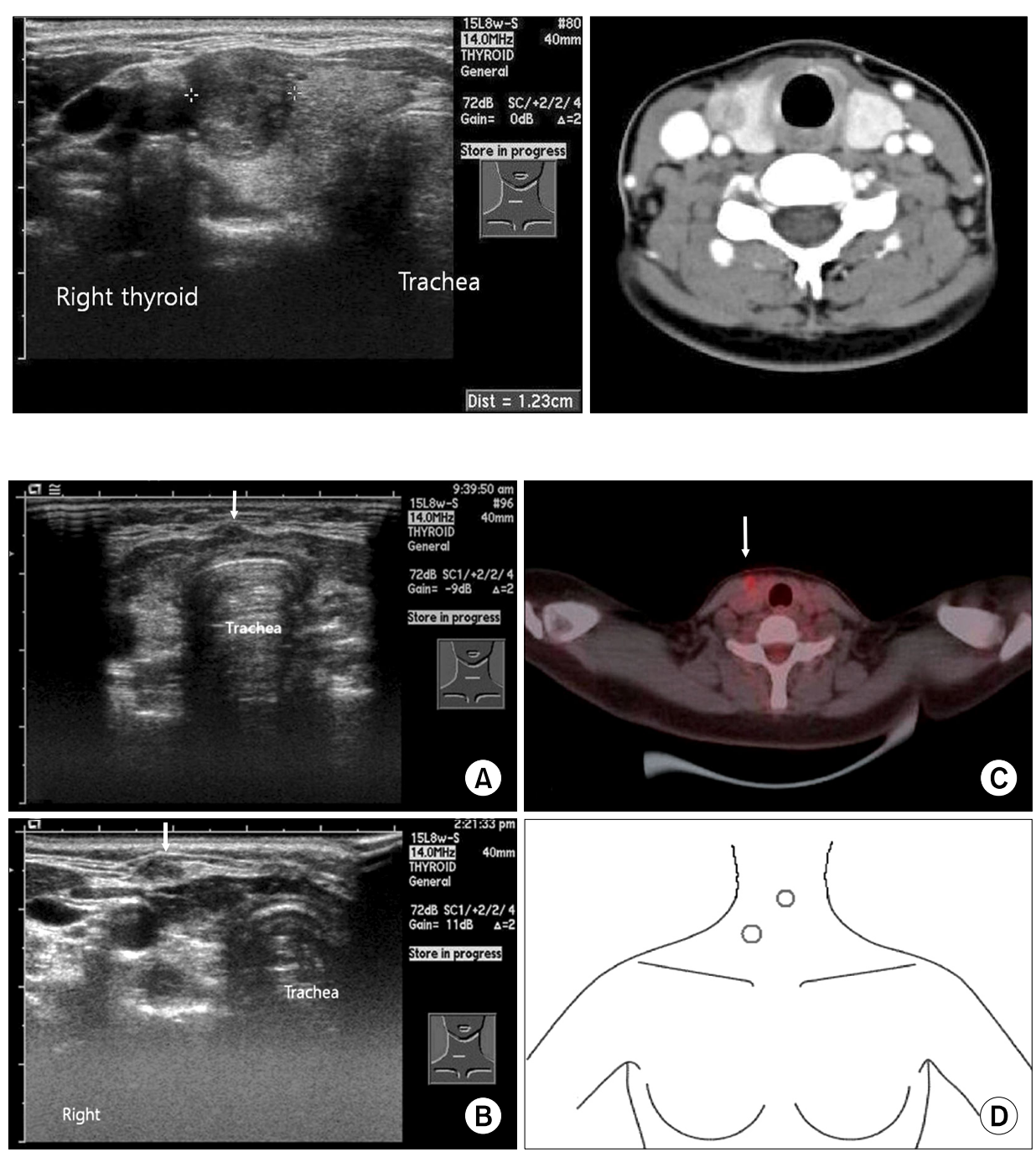

Fig. 1. Neck ultrasonography and neck computed tomography show a $17 \times 12 \times 13 \mathrm{~mm}$ sized oval-shaped, well demarcated solid nodule in the right upper portion of thyroid.
Fig. 2. The neck ultrasonography shows two nodules in the medial border of right sternocleido-mastoid (SCM) muscle, $6 \mathrm{~mm}$ sized in the anterior midline and with superior location of another nodule, about $5 \mathrm{~mm}$ sized $(A, B, D)$. The PET-CT shows a mildly hypermetabolic nodule at the medial border of right SCM muscle (C). 
metastases were confirmed on the permanent pathologic result. After the operation, the patient recovered well without complication, and there were no significances in the follow-up study. The serum TG was decreased. After excision of recurrent subcutaneous soft tissue nodules, we recommended low dose radioactive-iodine ablation $(30 \mathrm{mCi})$. However, the patient refused the radioactiveiodine ablation, so we decided to close follow up with USG, PET-CT and serum TG level.

In April 2011, three newly formed mildly hypermetabolic lesions in the skin and subcutaneous layer of medial and left sided neck were found on the PET-CT (Fig. 3A C, G) and the neck USG showed same suspicious lesions (Fig. 3D F). Also the serum TG was mildly increased (Fig. 4). So metastasis was suggested an USG-guided FNA was performed and PTC metastasis were revealed. These metastatic lesions were excised under local anesthesia through a small incision in the left lateral neck area without skin excision. The biopsy results showed these lesions were PTC metastasis on soft and skeletal tissue. No significances were found in follow-up study and serum TG was decreased after the operation (Fig. 4). At present, the
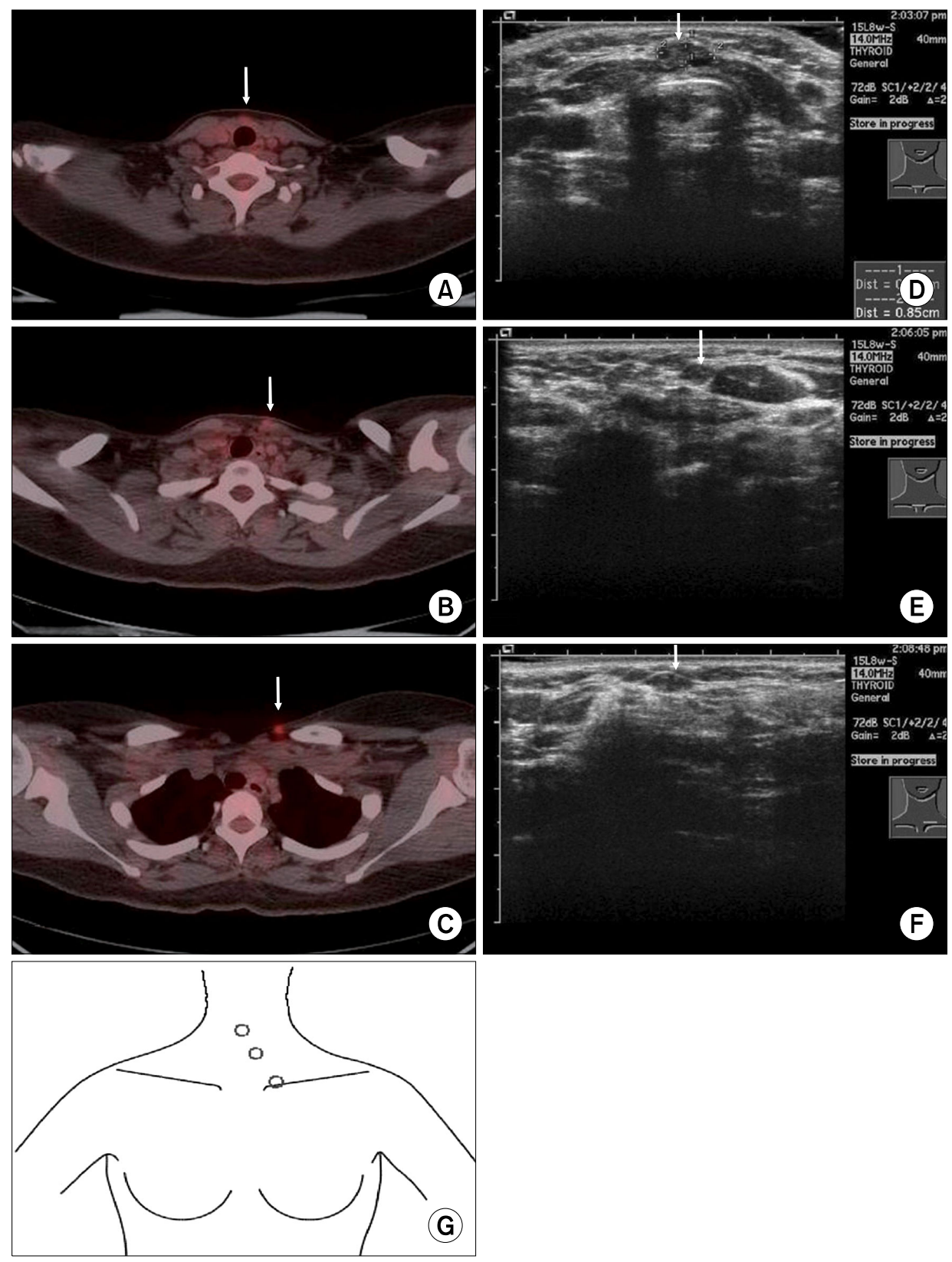

Fig. 3. The PETCT shows three newly formed mildly hypermetabolic lesions in the subcutaneous layer of medial and left sided neck and the skin (A $\sim C, G)$. The same suspicious lesion was noted on the neck USG (D F). 


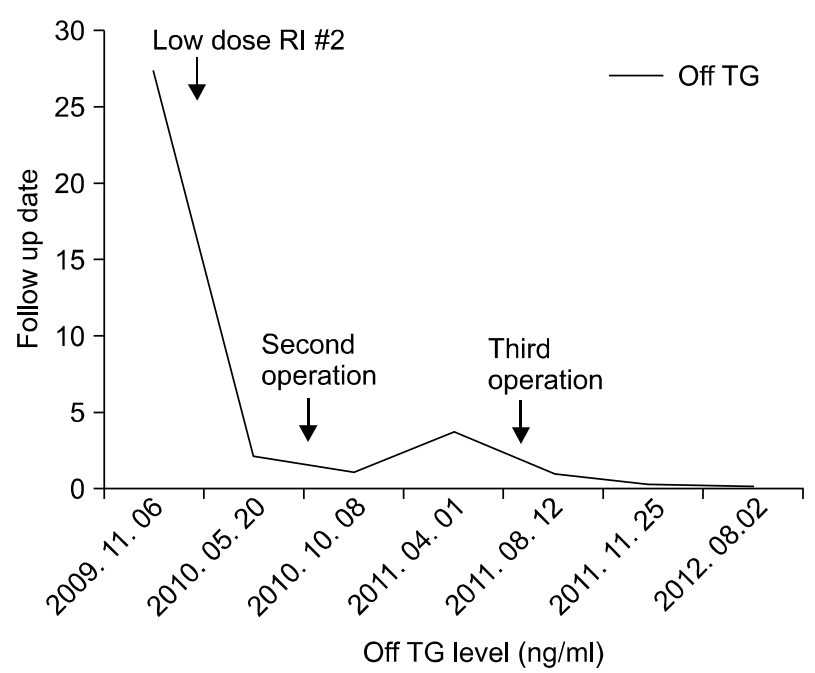

Fig. 4. Changes of serum TG according to recurrence and operation. Serum TG was stable after the third operation.

patient has no evidence of recurrence or metastasis.

\section{DISCUSSION}

In general, thyroid cancer, particularly PTC, grows slowly and has an excellent prognosis. Furthermore, a large percentage of PTC patients are young females. For this reason, quality of life after surgery, including cosmetic effects as well as the completeness of surgery has become an important issue regarding the treatment of PTC. Since the introduction of endoscopic neck surgery by Gagner ( 6 ) in the 1990s and the development of several approaches, endoscopic thyroid surgery has been widely used to treat thyroid diseases due to many advantages.

Recently, the number of patients undergoing endoscopic thyroid surgery is rapidly increasing because the postsurgical outcomes appear to be very similar to that of conventional open thyroid surgeries $(1,2)$ and the cosmetic effect is excellent.(3) However, as shown in our case, unexpected complications may occur, so it is important to establish proper indications when a decision is made for an endoscopic thyroid surgery. Several researchers recommend to establish a low-risk 11 thyroid carcinoma smaller than $1 \mathrm{~cm}$ as a proper indication also.(5)

Even though the cases of needle tract implantation of thyroid carcinoma after FNA have been occasionally reported, a soft tissue implantation on thyroid tissue is a very rare complication.(4)

Lee et al.( $\gg$ and Koh et al.( 8 ) reported the cases of soft tissue implantation at the site of port insertion in benign thyroid adenomatous hyperplasia after endoscopic thyroid surgery. Hur et al.(9) reported about cases where a soft tissue implantation occurred in thyroid follicular carcinoma. It is assumed that the complication may be caused by tumor manipulation, local trauma or rupture of thyroid tissue during the operation, by tumor biologic properties and the "chimney effect". $(10,11)$

According to the final pathologic result of this case, in which the capsule invasion and extrathyroidal extension occurred and the fact that the implantation site was located at the anterior side of the SCM and the strap muscle, the implantation cause in this case may be considered as a direct seeding due to manipulation rather than a chimney effect.

In conclusion, an endoscopic thyroid surgery may be regarded as an excellent surgical method in terms of treatment and cosmetic effect in the treatment of thyroid diseases. However, surgeons should keep in mind that a complication may occur, just like it was the case in our hospital. In addition, surgeons should keep in mind the several methods and tips to reduce tumor cell seeding such as careful manipulation of the thyroid specimen during operation, do not put the thyroid specimen on the operation field especially in thyroid cancer with extrathyroidal extension and packing of the thyroid tissue and lymph nodes into a bag during retrieval of the specimen. Accordingly, it is important for a clinician to identify the patients with potential indication before surgery. And if an endoscopic surgery is chosen, every effort should be made to reduce tumor cell seeding as much as possible.

\section{REFERENCES}

1. Choi JY, Lee KE, Chung KW, Kim SW, Choe JH, Koo do H, et al. Endoscopic thyroidectomy via bilateral axillo-breast approach (BABA): review of 512 cases in a single institute. Surg Endosc 2012;26:948-55.

2. Chung YS, Choe JH, Kang KH, Kim SW, Chung KW, Park KS, et al. Endoscopic thyroidectomy for thyroid malignancies: comparison with conventional open thyroidectomy. World J Surg 2007;31:2302-6. 
3. Jeong JJ, Kang SW, Yun JS, Sung TY, Lee SC, Lee YS, et al. Comparative study of endoscopic thyroidectomy versus conventional open thyroidectomy in papillary thyroid microcarcinoma (PTMC) patients. J Surg Oncol 2009;100:477-80.

4. Ito Y, Tomoda C, Uruno T, Takamura Y, Miya A, Kobayashi K, et al. Needle tract implantation of papillary thyroid carcinoma after fine-needle aspiration biopsy. World J Surg 2005;29:1544-9.

5. Choe JH, Kim SW, Chung KW, Park KS, Han W, Noh DY, et al. Endoscopic thyroidectomy using a new bilateral axillo-breast approach. World J Surg 2007;31:601-6.

6. Gagner M. Endoscopic subtotal parathyroidectomy in patients with primary hyperparathyroidism. Br J Surg 1996;83:875.

7. Lee YS, Yun JS, Jeong JJ, Nam KH, Chung WY, Park CS. Soft tissue implantation of thyroid adenomatous hyperplasia after en- doscopic thyroid surgery. Thyroid 2008;18:483-4.

8. Koh KW, Lee TH, Cho SY, Lee SS, Kim JM, Yi KH, et al. Subcutaneous implantation of adenomatous goiter: an unpredicted complication of endoscopic thyroid surgery. Thyroid 2010;20:441-3.

9. Hur SM, Kim SH, Lee SK, Kim WW, Choi JH, Kim JH, et al. Is a thyroid follicular neoplasm a good indication for endoscopic surgery? Surg Laparosc Endosc Percutan Tech 2011;21:e148-51.

10. Wille G, Miccoli P. Re: soft tissue implantation of thyroid adenomatous hyperplasia after endoscopic thyroid surgery. Thyroid 2009;19:313.

11. Schaeff B, Paolucci V, Thomopoulos J. Port site recurrences after laparoscopic surgery. A review. Dig Surg 1998;15:124-34. 